\title{
Is Individually-Targeted Food Assistance Shared among Family Members?
}

\author{
Jonathan V. Woodward, David C. Ribar
}

Department of Economics, University of North Carolina at Greensboro, Greensboro, USA.

Email: \{dcribar, jvwoodwa\}@uncg.edu

Received February $26^{\text {th }}, 2012$; revised April 10 ${ }^{\text {th }}, 2012$; accepted April $17^{\text {th }}, 2012$

\begin{abstract}
The Supplemental Nutrition Assistance Program (SNAP), the National School Lunch Program (NSLP), the School Breakfast Program (SBP), and the Special Supplemental Nutrition Program for Women, Infants, and Children (WIC) share a common goal of helping people with limited financial means obtain better diets than they could otherwise afford, but the programs differ in terms of the groups that they target and the types of assistance they provide. While the programs appear to increase food consumption among households generally and among their intended beneficiaries, we know much less about whether they help other people. This investigation uses 2002-2003 data from the second Child Development Supplement of the Panel Study of Income Dynamics to examine the relationship between households' participation in the SNAP, SBP, NLSP, and WIC and individual 10 - 17 year-old children's consumption of particular food items. Our analyses indicate that WIC participation by others in the household is associated with a 22 percent increase in breakfast consumption of milk and a 16 percent increase in breakfast consumption of cereal for the children in our sample, while WIC is associated with a 13 percent decrease in toast consumption. Participation in school meals is also associated with increased consumption of some foods, particularly juice, fruit, and sweet snacks. Household SNAP participation is estimated to have positive associations with some foods but negative associations with others.
\end{abstract}

Keywords: Food Assistance; Children's and Youth's Food Consumption; Sharing

\section{Introduction}

The US Department of Agriculture is responsible for several large food assistance programs. The programs with the greatest expenditures are the Supplemental Nutrition Assistance Program (SNAP, formerly the Food Stamp Program), the National School Lunch Program (NSLP), the School Breakfast Program (SBP), and the Special Supplemental Nutrition Program for Women, Infants, and Children (WIC) [1]. These programs share a common goal of helping people with limited financial means obtain better diets than they could otherwise afford, but they differ in terms of the groups that they target and the types of assistance they provide. The SNAP is intended to help low-income households generally, while the other three programs help specific groups. The NSLP and SBP are intended to improve nutritional outcomes for low-income school-age children, while WIC is intended to assist low-income pregnant, breastfeeding, and postpartum women and low-income infants and children up to age five.

A substantial amount of research has investigated whether and by how much these programs improve nutri- tional outcomes among their intended beneficiaries. Fox et al. [2] have summarized much of this research. They report, for instance, that studies of the SNAP indicate that each dollar of food assistance increases households' food spending, food consumption, and dietary intakes. Similarly, studies generally indicate that WIC increases dietary intakes among pregnant and post-partum women, infants, and young children and that the NSLP and SBP increase food consumption among school children. We know much less, however, about whether targeted assistance, such as the SBP, NSLP, and WIC, affects outcomes for non-targeted household members.

This investigation uses 2002-2003 data from the second Child Development Supplement (CDS-II) of the Panel Study of Income Dynamics (PSID) to examine the relationship between households' participation in the SNAP, SBP, NLSP, and WIC and individual 10 - 17 yearold children's consumption of particular food items. The CDS-II is useful for this research because it includes information on food consumption, participation in food assistance programs, household economic and demographic circumstances, and other characteristics. The variety of measures allows us to control for many ob- 
served characteristics of households in multivariate analyses.

\section{Background}

Social scientists conceptualize that targeted and nontargeted food assistance may affect individual household members' food consumption in a number of ways. The first and intended manner is by increasing the amount of food available to the targeted beneficiaries. Indeed, there is evidence across a vast number of studies that all of the programs are associated with increased food consumption and higher intakes of at least some nutrients for their intended beneficiaries [2]. However, the evidence, especially regarding WIC, is far from conclusive and many of the associations are modest in size [3].

The programs may also increase the availability of food for non-targeted individuals living in assistance households. Especially relevant for our study are the foods from a family's WIC package. The packages contain particular types of foods - at the time of our study, formula, infant cereal and baby foods for beneficiaries who are infants and juice, milk, regular cereal, eggs, and legumes for beneficiaries who are mothers or small children [4]. While it is doubtful that infant foods would be consumed by older children or other household members, the non-infant food items might be available to and eaten by others. This would have the effect of raising food consumption among the non-targeted beneficiaries and lowering it among the targeted beneficiaries. This latter effect would undermine the goals of WIC ${ }^{1}$.

A second way in which food assistance participation could affect different household members' food outcomes is through its effect on overall household income. Expenditures that might have gone toward meals for targeted beneficiaries might be redirected toward food consumption for other household members. Social scientists have long recognized that household expenditures are fungible. If a household allocates positive amounts of its own money to food in the absence of program benefits, it has the flexibility to reduce those expenditures (and increase other expenditures) should it receive program benefits. For example, Long [5] reported that households reduced their other food expenditures by 61 cents for each dollar's worth of NSLP benefits. Fox et al. [2] summarize research that indicates that households' propensity to spend SNAP assistance on food consumption is substantially less than dollar-for-dollar.

Oliveira and Chandran [4] and VerPloeg [6] have suggested that the nutrition education components of WIC and other programs represent a third way by which

\footnotetext{
${ }^{1}$ Similar effects can occur in households in which some but not all of the people are members of a SNAP assistance unit. They are also possible in school meal and summer food service programs with "backpack" features.
}

participation in targeted programs can affect different household members' food consumption. The educational components may increase adults' awareness of their households' nutritional needs causing them to allocate more money toward food expenditures. The educational components could also help adults to use food more efficiently and to monitor children's consumption more carefully. Each of these effects could result in more food consumption.

In addition to these causal explanations for associations between food assistance participation and different household members' food consumption, we must also recognize that non-causal mechanisms, including reverse causality and spurious correlations owing to omitted characteristics, may lead to associations. Participation in the SBP, NSLP, WIC and SNAP each require active steps by households. Households with stronger preferences regarding food consumption or with greater food needs would be more motivated and more likely to participate in these programs than other households. The observed association between food assistance and food consumption could reflect these underlying characteristics.

A number of studies have either directly or indirectly examined the possible substitution between food assistance and non-targeted household members' food consumption. Among the indirect studies, Oliveira and Gundersen investigated the relationship between WIC participation and young children's food consumption, comparing outcomes for targeted and non-targeted children in WIC-receiving households. Oliveira and Gundersen were concerned about the selectivity of WIC eligibility and participation and posited that non-targeted children in WIC-receiving households could serve as a suitable control group for targeted children. The researchers found that the consumption of several nutrients was higher among targeted children than non-targeted children in these households. Interestingly, however, the estimates from their study also indicated that intakes of several nutrients for their control group of non-targeted children living in WIC households were lower than the intakes for children of similar ages living in income-eligible but non-participating households. This latter comparison suggests that non-targeted children do not benefit from household WIC participation [7].

Arcia et al. also examined substitution indirectly. The researchers estimated multivariate models of households' expenditures on all foods, groceries, and meals away from home that included indicators for WIC receipt and interactions of the WIC indicator with the numbers of children and adults in the household. They interpreted the coefficients on the interactions as indirect measures of sharing. The estimates, however, did not yield any evidence of sharing [8]. 
Ishdorj et al. investigated substitution more directly, examining calcium intakes among targeted family members in WIC households, non-targeted family members in WIC households, and others in income-eligible, nonWIC households and employing multivariate estimation procedures that accounted for the endogeneity of WIC participation. Ishdorj et al. failed to uncover evidence of substitution, finding that calcium intakes were lower among non-targeted family members in WIC households than among others in non-WIC households [9].

In contrast to these results, Oliveira and Chandran [4] were able to detect evidence of substitution between young targeted and non-targeted children in their consumption of WIC-approved cereal and juice. VerPloeg [6] examined food consumption behaviors associated with the Healthy Eating Index (HEI) among children aged 5 17 years who lived in households that did and did not receive WIC. The key advantage of VerPloeg's study design was that it was limited to children who were necessarily non-targeted for WIC by virtue of their ages. She found evidence of substitution in grains, fruits, cholesterol, and the total HEI. She also found that food intakes were higher if the children lived in households with multiple WIC recipients rather than a single recipient and in households with non-infant recipients rather than infant recipients.

Rose et al. [10] investigated another form of substitution, examining the effects of household SNAP, WIC and NSLP participation on nutrient intakes of children aged 1 4 years. The researchers found that NSLP participation by other children in the household was associated with higher intakes of iron and zinc. Bhattacharya et al. [11] examined the SBP and found that children's participation was associated with adults' eating behavior.

\section{Data}

For this study, we examine food consumption among children who were respondents in the second (2002-2003) wave of the Child Development Supplement to the Panel Study of Income Dynamics. The PSID is a national, longitudinal survey, which began with 5000 households in 1968. Since then, those households and the new households formed from the original sample members and their descendants have been followed in annual interviews through 1997 and biennial interviews thereafter. In 1997, a supplemental set of interviews, the CDS-I, was conducted to collect information on 3563 children in PSID families aged 0 - 12. Five years later, a second wave, the CDS-II, was conducted with 2907 of the CDS-I children.

The instruments in the CDS-II included a Child Interview (CI) that was administered directly to the focal children and a Primary Caregiver (PCG) interview that was administered to one of the child's guardians. Respondent children to the CI who were ten years or older were asked about foods usually consumed for breakfast and over the preceding week ${ }^{2}$.

Of the children who participated in the CDS-II, about a third (956) were five to nine years old and, thus, too young to answer the questions about food consumption. A further 207 age-eligible children did not complete the CI, leaving 1744 children with information on food outcomes. For our analysis dataset, we combine information from the CI for these children with available information from the PCG interview and with household economic and demographic information from later waves of the PSID. We drop some children whose households did not participate in later waves of the PSID. Because of our interest in studying the effects of the NLSP and SBP, we also drop children who were not enrolled in elementary or secondary school or were older than 17 years. We also drop children with item non-response for food consumption or program participation. The final analysis sample includes 1582 children aged 10 - 17 years for the breakfast consumption analyses and slightly fewer observations for the weekly food consumption analyses.

We use responses from two sets of CDS questions to analyze children's eating behaviors. The first asked, "What do you usually have for breakfast on a weekday morning?" Children could indicate (yes/no) whether they consumed milk, coffee, juice, cereal, toast, fruit, eggs, meat, snack food, or other food. The second question asked how often children ate particular foods in a week. "Think about all of the food that you ate last week, including meals and snacks at home, at school, at restaurants, and anywhere else. How many days last week did you eat/drink..." with the listed foods being milk and dairy, fruit, vegetables, grains, sweets, meat, and other protein (eggs, peanut butter, beans, and soy). The possible answers were the numbers of days from zero to seven.

A critical advantage of the PSID is that it also has information about several different types of government food assistance that the family may have received, including WIC, free and reduced-price school breakfasts and lunches, and SNAP. We measure receipt of the first three types of assistance using binary variables. In particular, we include a binary indicator for whether the family reported that at least one woman or child received WIC assistance in 2002. For each type of school meal, the CDS asks first whether the child ate the meals at school and second whether the meals were received for free or at a reduced price. We use these measures to create dummy variables that indicate whether the child re-

\footnotetext{
${ }^{2} \mathrm{~A}$ third supplement, the CDS-III, was fielded in 2007 and asked about children's breakfast and weekly food consumption. However, our analysis of the CDS-III indicated that its food data were unreliable.
} 
ceived free or reduced-price breakfasts and lunches. The omitted categories would include children who did not eat school meals or who paid the regular price for those meals. To characterize benefits under the SNAP, we create two measures. First, we create a binary indicator of whether the child's family received SNAP in the year of the CDS child interview. Second, we create a continuous measure of the value of the SNAP benefits received that year expressed as a proportion of the family's size- and age-adjusted poverty standard.

Table 1 lists means of the food consumption measures for the entire study sample and for different groups conditional on their receipt of food assistance. The figures differ modestly from estimates reported in other surveys. For example, our data from the CDS-II indicate that 41.5 percent of 10 - 17 year olds "usually" had milk for breakfast, while 2001-2002 diary data from the National Health and Nutrition Examination Survey (NHANES) indicate that 53 percent of 12 - 19 year-olds reported having milk at breakfast [12]. Reports from the CDS-II for coffee, juice, cereal, toast, fruit, and eggs are higher than the corresponding values from the NHANES. Differences in the question (usual consumption versus a given day's consumption), the instrument (short recall questions versus a diary), and the identification of meals (the NHANES asks about eating episodes and then asks people to describe the type of meal) could account for the differences in values.

Comparisons of the conditional means reveal that children in WIC households report consuming more milk and snacks for breakfast than children in non-WIC households, but WIC children also report consuming less toast. Children who receive two school meals report consuming more juice, eggs, meat, and snacks for breakfast and less toast than children who do not receive school meals. Children who receive two school meals also report consuming milk, vegetables and grains on fewer days per week than children who do not receive school meals. Children in SNAP households report eating less toast for breakfast and consuming milk, vegetables, and grains on

Table 1. Means of usual breakfast and weekly food consumption.

\begin{tabular}{|c|c|c|c|c|c|c|c|c|}
\hline & (1) & (2) & (3) & (4) & (5) & (6) & (7) & (8) \\
\hline Usual Breakfast & All Obs & No WIC & Received WIC & 0 School Meals & 1 School Meal & 2 School Meals & No SNAP & Received SNAP \\
\hline Milk & $41.5 \%$ & $40.7 \%$ & $56.9 \%^{*}$ & $39.6 \%$ & $43.5 \%$ & $47.0 \%$ & $41.8 \%$ & $38.7 \%$ \\
\hline Coffee & $9.5 \%$ & $9.2 \%$ & $13.4 \%$ & $8.2 \%$ & $11.7 \%$ & $12.2 \%$ & $9.0 \%$ & $13.7 \%$ \\
\hline Juice & $40.2 \%$ & $39.8 \%$ & $48.4 \%$ & $39.1 \%$ & $33.7 \%$ & $49.7 \%{ }^{* *}$ & $39.9 \%$ & $43.0 \%$ \\
\hline Cereal & $46.1 \%$ & $45.8 \%$ & $52.4 \%$ & $45.7 \%$ & $45.1 \%$ & $48.4 \%$ & $46.5 \%$ & $42.8 \%$ \\
\hline Toast & $34.6 \%$ & $35.4 \%$ & $19.0 \%{ }^{* *}$ & $37.5 \%$ & $29.4 \%{ }^{*}$ & $28.0 \%^{* *}$ & $36.1 \%$ & $22.3 \%^{* * *}$ \\
\hline Fruit & $19.9 \%$ & $19.5 \%$ & $28.8 \%$ & $18.7 \%$ & $18.9 \%$ & $25.5 \%{ }^{*}$ & $19.9 \%$ & $20.5 \%$ \\
\hline Eggs & $23.5 \%$ & $23.4 \%$ & $25.5 \%$ & $21.1 \%$ & $22.1 \%$ & $33.4 \%^{* * *}$ & $22.5 \%$ & $31.4 \%$ \\
\hline Meat & $10.1 \%$ & $10.0 \%$ & $12.2 \%$ & $8.3 \%$ & $11.8 \%$ & $15.4 \%^{* *}$ & $9.7 \%$ & $13.5 \%$ \\
\hline Snacks & $16.0 \%$ & $15.1 \%$ & $34.2 \%{ }^{* *}$ & $13.9 \%$ & $17.9 \%$ & $22.6 \%{ }^{* *}$ & $15.6 \%$ & $19.4 \%$ \\
\hline Other & $16.2 \%$ & $16.8 \%$ & $5.8 \%{ }^{* * *}$ & $19.0 \%$ & $12.2 \%{ }^{* *}$ & $8.9 \%{ }^{* * *}$ & $17.3 \%$ & $7.3 \%{ }^{* * *}$ \\
\hline Days/Week & All Obs & No WIC & Received WIC & 0 School Meals & 1 School Meal & 2 School Meals & No SNAP & Received SNAP \\
\hline Milk & 5.4 & 5.4 & 5.2 & 5.5 & $5.0^{* *}$ & $4.9^{* * *}$ & 5.4 & $4.8^{* * *}$ \\
\hline Fruit & 4.9 & 4.9 & 4.9 & 4.9 & 4.8 & 5.0 & 4.9 & 5.0 \\
\hline Vegetables & 4.1 & 4.1 & 3.9 & 4.3 & 4.0 & $3.7^{* * *}$ & 4.2 & $3.4^{* * *}$ \\
\hline Grains & 5.8 & 5.8 & 5.3 & 6.0 & $5.6^{* *}$ & $5.3^{* * *}$ & 5.9 & $5.3^{* *}$ \\
\hline Sweets & 4.7 & 4.7 & 4.1 & 4.7 & $4.3^{*}$ & 4.8 & 4.7 & 4.6 \\
\hline Meat & 5.2 & 5.2 & 4.7 & 5.2 & 5.2 & 5.0 & 5.2 & 5.0 \\
\hline Protein & 3.6 & 3.6 & 3.7 & 3.6 & 3.8 & 3.7 & 3.7 & 3.6 \\
\hline
\end{tabular}

Note: Authors' calculations of the percentages of children aged 10 - 17 years in the 2002 CDS-II who reported usually consuming the listed food for breakfast (top panel) and means of the number of days those children ate the listed foods in the week preceding the interview. All of the statistics were calculated using sample weights provided with the PSID. Asterisks indicate whether the percentages or means are significantly different for children receiving food assistance relative to those who do not. ${ }^{* * *} \mathrm{p}<0.01 ;{ }^{* *} \mathrm{p}<0.05 ;{ }^{*} \mathrm{p}<0.1$. 
fewer days than children in non-SNAP households.

The differences in food consumption could be attributable to other characteristics of the children besides food assistance. To address this possibility, we conduct multivariate analyses that include many other measures that are likely to influence children's food consumption and are also likely to be associated with participation in food assistance programs. We control for family economic resources by including the ratio of family's income in 2002 (measured in the PSID as the sum of its earned income, unearned income and cash transfers) to its needs (measured by the Census Bureau estimate of the poverty level for a family of that size and age distribution). In addition to the continuous measure of the income-to-needs ratio, we include indicators for whether the ratio is below 1.3 and whether it is between 1.3 and 1.85 , as these are standard food assistance eligibility thresholds.

We control for family composition through the use of four variables: the number of children in the family who are aged 0 - 5 years, the number of children who are aged $6-18$ years, the number of adults who are 19 years or older, and an indicator for whether the family head is married. To account for time inputs and supervision from the parents, we also include indicators for the employment status of the head and of the spouse, if present. We also control for six education categories of the family head: did not attend high school, did not graduate from high school, graduated from high school or got a GED, attended but did not graduate from college, graduated from college, and received a graduate degree. There were 54 children with family heads for whom the education level was unknown; we include an indicator variable for this situation. We also include standard demographic and geographic controls, including measures of the child's gender and age, race and ethnicity, geographic region, and urban residence. Table 2 lists means of the independent variables for our analysis for the entire study sample and for groups of children conditional on their participation in food assistance programs.

\section{Multivariate Analyses}

To estimate how food assistance and our other independent variables are associated with the foods that children report usually eating for breakfast, we use linear probability (ordinary least squares, OLS) models. These multivariate models incorporate sample weights provided with the CDS, in order to be nationally representative. They include standard errors that are heteroskedasticityrobust and are clustered by family in the PSID, since two children from the same family may not have independent eating behaviors. Our multivariate analyses of weekly food consumption also use OLS with sample weights and robust and clustered standard errors.

One possible concern with the use of OLS for these analyses is that our outcomes are categorical—binary outcomes for breakfast consumption and counts from zero to seven for days of weekly consumption. OLS has the disadvantage of possibly predicting outside the range of the dependent variables and being inefficient. However, the coefficient estimates from the OLS model can be directly interpreted as marginal effects. OLS is also consistent and robust to alternative assumptions regarding the model errors. In sensitivity analyses (not shown but available upon request), we re-estimated all of our OLS specifications using probit and ordered-probit models, with no substantive changes in the results.

Table 3 lists coefficient estimates from linear probability models of the determinants of children's consumption of different breakfast foods. The columns list results for models in which the dependent variables (from left to right) are the consumption of milk and other dairy products, coffee, juice, bread or toast, fruit, eggs, meat, snacks, or other foods. The rows list coefficients from our programmatic, economic, demographic, and geographic explanatory variables.

We begin by considering the results for the food assistance measures. Estimates from the first row indicate that children who received free or reduced-price school breakfasts reported having a statistically significant 14 percent higher probability of drinking juice with breakfast, a 10 percent higher probability of consuming fruit, and an eight percent higher probability of consuming snacks. SBP participation is estimated to be positively associated with the consumption of most other foods, but the estimates are not statistically different from zero.

Estimates from the regressions also indicate that participation in the school lunch program is associated with significantly higher reported levels of milk and dairy consumption $(+13 \%)$ at breakfast. One interpretation of this result is that participation in the NSLP frees up household resources so that poor families can afford to provide their children with milk. The estimate could also reflect children being exposed to milk in their school lunches and consequently having more favorable attitudes about milk at other times.

Relative to the rest of the children in the full sample, children who were in a family that included one or more people who received WIC reported significantly higher probabilities of consuming dairy products $(+22 \%)$, cereal $(+16 \%)$, and snack foods $(+18 \%)$ for breakfast but a lower probability of usually eating toast $(-13 \%)$. The results for milk and cereal are consistent with substitution from WIC increasing the availability of these specific foods, which were available in the WIC package at the time of our study. The results are also consistent with children substituting cereal for bread in the morning. 
Table 2. Means of independent variables.

\begin{tabular}{|c|c|c|c|c|c|c|c|c|}
\hline \multirow{2}{*}{ VARIABLES } & (1) & $(2)$ & (3) & (4) & (5) & (6) & (7) & (8) \\
\hline & All Obs & No WIC & Rec. WIC & 0 Sch. Meals & 1 Sch. Meal & 2 Sch. Meals & No SNAP & Rec. SNAP \\
\hline Free/Reduced School Breakfast & 0.191 & 0.168 & 0.634 & 0.000 & 0.072 & 1.000 & 0.139 & 0.624 \\
\hline Free/Reduced School Lunch & 0.312 & 0.283 & 0.876 & 0.000 & 0.928 & 1.000 & 0.251 & 0.829 \\
\hline Received WIC & 0.049 & 0.000 & 1.000 & 0.007 & 0.105 & 0.165 & 0.029 & 0.223 \\
\hline Received SNAP & 0.106 & 0.086 & 0.479 & 0.023 & 0.191 & 0.351 & 0.000 & 1.000 \\
\hline SNAP Value/Needs & 0.014 & 0.010 & 0.081 & 0.003 & 0.023 & 0.047 & 0.000 & 0.128 \\
\hline Ratio of Income/Needs & 4.154 & 4.306 & 1.228 & 5.196 & 2.603 & 1.468 & 4.502 & 1.208 \\
\hline $130 \%<$ Income $/$ Needs $<185 \%$ & 0.097 & 0.085 & 0.338 & 0.034 & 0.272 & 0.197 & 0.096 & 0.111 \\
\hline Income $/$ Needs $<130 \%$ & 0.172 & 0.155 & 0.490 & 0.052 & 0.287 & 0.529 & 0.112 & 0.677 \\
\hline \# of Children Age $<6$ & 0.173 & 0.121 & 1.163 & 0.106 & 0.261 & 0.353 & 0.141 & 0.438 \\
\hline \# of Children Age $>5,<19$ & 2.087 & 2.044 & 2.906 & 1.931 & 2.326 & 2.484 & 2.014 & 2.698 \\
\hline$\#$ of Adults Age $>18$ & 2.038 & 2.039 & 2.022 & 2.090 & 1.976 & 1.895 & 2.091 & 1.594 \\
\hline Family Head Is Married & 0.749 & 0.750 & 0.729 & 0.831 & 0.615 & 0.544 & 0.793 & 0.375 \\
\hline Head Is Employed & 0.855 & 0.861 & 0.729 & 0.907 & 0.805 & 0.698 & 0.892 & 0.540 \\
\hline Wife Is Employed & 0.554 & 0.568 & 0.280 & 0.671 & 0.438 & 0.206 & 0.608 & 0.099 \\
\hline Head Had No High School & 0.065 & 0.046 & 0.445 & 0.009 & 0.160 & 0.204 & 0.051 & 0.185 \\
\hline Head Did Not Graduate H.S. & 0.070 & 0.068 & 0.126 & 0.033 & 0.134 & 0.160 & 0.061 & 0.149 \\
\hline Head Had Some College & 0.200 & 0.208 & 0.045 & 0.220 & 0.189 & 0.134 & 0.206 & 0.154 \\
\hline Head Graduated from College & 0.263 & 0.271 & 0.099 & 0.351 & 0.117 & 0.048 & 0.289 & 0.043 \\
\hline Head Received Graduate Degree & 0.067 & 0.071 & 0.000 & 0.099 & 0.000 & 0.001 & 0.074 & 0.012 \\
\hline No Data on Head's Education & 0.027 & 0.027 & 0.023 & 0.023 & 0.034 & 0.037 & 0.028 & 0.017 \\
\hline Female & 0.500 & 0.492 & 0.671 & 0.488 & 0.472 & 0.570 & 0.492 & 0.573 \\
\hline Child's Age at Interview & 13.589 & 13.594 & 13.496 & 13.858 & 13.293 & 12.814 & 13.649 & 13.082 \\
\hline Child Is Black & 0.176 & 0.170 & 0.295 & 0.089 & 0.292 & 0.412 & 0.146 & 0.437 \\
\hline Child Is Hispanic & 0.131 & 0.108 & 0.576 & 0.049 & 0.276 & 0.322 & 0.111 & 0.294 \\
\hline Central Region & 0.242 & 0.246 & 0.162 & 0.268 & 0.278 & 0.115 & 0.248 & 0.196 \\
\hline Southern Region & 0.327 & 0.330 & 0.267 & 0.291 & 0.291 & 0.493 & 0.315 & 0.428 \\
\hline Western Region & 0.253 & 0.244 & 0.439 & 0.241 & 0.237 & 0.313 & 0.251 & 0.277 \\
\hline Rural Area & 0.280 & 0.281 & 0.252 & 0.281 & 0.212 & 0.327 & 0.275 & 0.317 \\
\hline
\end{tabular}

Note: Authors' calculations of the means of the listed characteristics for children aged 10 - 17 years in the 2002 CDS-II. Omitted categories are high school graduate, white, and North-East region. All of the statistics were calculated using sample weights provided with the PSID.

The associations between SNAP and foods consumed are more difficult to interpret, because our models control for both receiving SNAP and for the needs-adjusted value of the benefits received. Surprisingly, the estimates indicate that the receipt of SNAP is negatively associated with the consumption of toast and fruit. The estimates also indicate that higher levels of SNAP benefits, conditional on receipt, are associated with increased consump- tion of juice and fruit but decreased consumption of cereal. If we evaluated the coefficients for SNAP receipt and benefits at the average value of the needs-adjusted benefit level for participating households, the net associations of SNAP and foods consumed at breakfast are close to zero.

When we examine the coefficients for the other variables, we see that children in households with incomes 
Table 3. Linear models of breakfast consumption.

\begin{tabular}{|c|c|c|c|c|c|c|c|c|c|c|}
\hline \multirow{2}{*}{ VARIABLES } & (1) & (2) & (3) & (4) & (5) & (6) & (7) & (8) & (9) & (10) \\
\hline & Milk & Coffee & Juice & Cereal & Toast & Fruit & Eggs & Meat & Snacks & Other \\
\hline \multirow{2}{*}{ School Breakfast } & 0.020 & 0.012 & $0.140^{* *}$ & 0.089 & 0.001 & $0.098^{* *}$ & 0.054 & 0.041 & $0.082^{*}$ & -0.023 \\
\hline & $(0.060)$ & $(0.040)$ & $(0.056)$ & $(0.058)$ & $(0.052)$ & $(0.050)$ & $(0.053)$ & $(0.036)$ & $(0.044)$ & $(0.037)$ \\
\hline \multirow{2}{*}{ School Lunch } & $0.125^{* *}$ & 0.014 & -0.046 & 0.001 & 0.032 & -0.019 & -0.004 & 0.006 & -0.017 & -0.025 \\
\hline & $(0.058)$ & $(0.035)$ & $(0.050)$ & $(0.050)$ & $(0.052)$ & $(0.042)$ & $(0.046)$ & $(0.031)$ & $(0.042)$ & $(0.034)$ \\
\hline \multirow{2}{*}{ Received WIC } & $0.217^{* *}$ & 0.019 & 0.083 & $0.159^{*}$ & $-0.132^{*}$ & -0.007 & -0.004 & 0.044 & $0.178^{* *}$ & -0.061 \\
\hline & $(0.099)$ & $(0.065)$ & $(0.088)$ & $(0.095)$ & $(0.072)$ & $(0.079)$ & $(0.084)$ & $(0.052)$ & $(0.072)$ & $(0.047)$ \\
\hline \multirow{2}{*}{ Received SNAP } & -0.159 & -0.041 & -0.128 & 0.110 & $-0.155^{*}$ & $-0.127^{* *}$ & 0.018 & 0.032 & 0.022 & -0.022 \\
\hline & $(0.101)$ & $(0.052)$ & $(0.084)$ & $(0.093)$ & $(0.091)$ & $(0.062)$ & $(0.108)$ & $(0.070)$ & $(0.066)$ & $(0.055)$ \\
\hline \multirow{2}{*}{ SNAP Value/Needs } & 0.451 & 0.231 & $0.890^{*}$ & $-1.083^{* *}$ & 0.396 & $0.875^{* *}$ & -0.030 & -0.343 & -0.322 & 0.114 \\
\hline & $(0.614)$ & $(0.390)$ & $(0.512)$ & $(0.512)$ & $(0.533)$ & $(0.442)$ & $(0.740)$ & $(0.521)$ & $(0.377)$ & $(0.333)$ \\
\hline \multirow{2}{*}{ Income/Needs } & -0.000 & -0.001 & $0.006^{* * *}$ & -0.002 & -0.000 & -0.001 & -0.002 & -0.000 & $-0.002^{*}$ & -0.001 \\
\hline & $(0.002)$ & $(0.001)$ & $(0.002)$ & $(0.002)$ & $(0.003)$ & $(0.002)$ & $(0.002)$ & $(0.002)$ & $(0.001)$ & $(0.001)$ \\
\hline \multirow{2}{*}{$\begin{array}{l}\text { Income/Needs Is } \\
>1.3 \&<1.85\end{array}$} & -0.057 & -0.001 & 0.037 & -0.046 & -0.066 & 0.006 & -0.050 & 0.029 & -0.015 & $0.085^{*}$ \\
\hline & $(0.062)$ & $(0.038)$ & $(0.057)$ & $(0.059)$ & $(0.057)$ & $(0.043)$ & $(0.049)$ & $(0.032)$ & $(0.047)$ & $(0.045)$ \\
\hline \multirow{2}{*}{ Income/Needs Is $<1.3$} & -0.057 & $0.087^{* *}$ & -0.052 & -0.047 & -0.048 & $-0.074^{*}$ & -0.042 & 0.013 & -0.069 & 0.004 \\
\hline & $(0.057)$ & $(0.043)$ & $(0.058)$ & $(0.062)$ & $(0.062)$ & $(0.040)$ & $(0.052)$ & $(0.037)$ & $(0.046)$ & $(0.045)$ \\
\hline \multirow{2}{*}{ \# of Children $<6$} & -0.040 & -0.023 & -0.028 & -0.030 & $0.066^{*}$ & 0.037 & -0.029 & -0.015 & -0.009 & 0.016 \\
\hline & $(0.035)$ & $(0.017)$ & $(0.036)$ & $(0.036)$ & $(0.037)$ & $(0.031)$ & $(0.032)$ & $(0.020)$ & $(0.025)$ & $(0.026)$ \\
\hline \multirow{2}{*}{$\begin{array}{l}\text { \# of Children between } \\
6 \text { and } 18\end{array}$} & $0.038^{* *}$ & 0.000 & 0.024 & 0.028 & 0.013 & $0.046^{* * *}$ & -0.003 & 0.004 & 0.002 & -0.017 \\
\hline & $(0.016)$ & $(0.011)$ & $(0.017)$ & $(0.018)$ & $(0.018)$ & $(0.013)$ & $(0.015)$ & $(0.011)$ & $(0.012)$ & $(0.012)$ \\
\hline \multirow{2}{*}{$\#$ of Adults $>18$} & -0.009 & -0.008 & 0.038 & 0.031 & $-0.051^{* *}$ & 0.019 & 0.014 & 0.012 & 0.016 & -0.004 \\
\hline & $(0.027)$ & $(0.016)$ & $(0.028)$ & $(0.027)$ & $(0.025)$ & $(0.022)$ & $(0.025)$ & $(0.021)$ & $(0.020)$ & $(0.019)$ \\
\hline \multirow{2}{*}{ Head Is Married } & 0.023 & 0.004 & -0.052 & -0.025 & 0.072 & 0.009 & 0.011 & -0.027 & -0.050 & 0.016 \\
\hline & $(0.062)$ & $(0.037)$ & $(0.063)$ & $(0.063)$ & $(0.055)$ & $(0.045)$ & $(0.057)$ & $(0.037)$ & $(0.046)$ & $(0.045)$ \\
\hline \multirow{2}{*}{ Head Is Employed } & -0.025 & -0.035 & 0.004 & 0.058 & -0.061 & 0.020 & $-0.112^{* *}$ & -0.012 & -0.015 & $0.083^{* * *}$ \\
\hline & $(0.051)$ & $(0.040)$ & $(0.048)$ & $(0.046)$ & $(0.052)$ & $(0.033)$ & $(0.047)$ & $(0.032)$ & $(0.036)$ & $(0.028)$ \\
\hline \multirow{2}{*}{ Wife Is Employed } & $-0.077^{*}$ & -0.020 & -0.033 & 0.014 & -0.030 & -0.008 & 0.000 & -0.003 & 0.034 & 0.017 \\
\hline & $(0.046)$ & $(0.028)$ & $(0.044)$ & $(0.046)$ & $(0.041)$ & $(0.036)$ & $(0.039)$ & $(0.026)$ & $(0.033)$ & $(0.034)$ \\
\hline \multirow{2}{*}{$\begin{array}{l}\text { Head Did Not Attend } \\
\text { High School }\end{array}$} & $-0.205^{* *}$ & -0.014 & -0.117 & -0.040 & $-0.176^{* *}$ & $-0.145^{* *}$ & -0.108 & 0.030 & $-0.116^{*}$ & 0.003 \\
\hline & $(0.089)$ & $(0.070)$ & $(0.077)$ & $(0.091)$ & $(0.077)$ & $(0.069)$ & $(0.078)$ & $(0.043)$ & $(0.067)$ & $(0.046)$ \\
\hline \multirow{2}{*}{$\begin{array}{l}\text { Head Did Not Grad. } \\
\text { High School }\end{array}$} & 0.008 & 0.012 & $-0.154^{* *}$ & -0.035 & $-0.099^{*}$ & -0.027 & -0.012 & 0.010 & -0.033 & 0.030 \\
\hline & $(0.066)$ & $(0.045)$ & $(0.065)$ & $(0.065)$ & $(0.055)$ & $(0.047)$ & $(0.061)$ & $(0.043)$ & $(0.048)$ & $(0.048)$ \\
\hline \multirow{2}{*}{$\begin{array}{l}\text { Head Attended Some } \\
\text { College }\end{array}$} & 0.003 & -0.004 & -0.019 & -0.027 & 0.024 & 0.036 & 0.036 & 0.022 & -0.029 & -0.026 \\
\hline & $(0.043)$ & $(0.027)$ & $(0.043)$ & $(0.046)$ & $(0.046)$ & $(0.033)$ & $(0.039)$ & $(0.024)$ & $(0.034)$ & $(0.034)$ \\
\hline
\end{tabular}




\section{Continued}

\begin{tabular}{|c|c|c|c|c|c|c|c|c|c|c|}
\hline \multirow{2}{*}{$\begin{array}{l}\text { Head Is College } \\
\text { Graduate }\end{array}$} & 0.009 & 0.031 & -0.028 & 0.000 & 0.031 & 0.044 & -0.003 & 0.033 & -0.036 & -0.043 \\
\hline & $(0.045)$ & $(0.030)$ & $(0.046)$ & $(0.046)$ & $(0.048)$ & $(0.035)$ & $(0.039)$ & $(0.029)$ & $(0.033)$ & $(0.033)$ \\
\hline \multirow{2}{*}{$\begin{array}{l}\text { Head Has a Graduate } \\
\text { Degree }\end{array}$} & $0.183^{* *}$ & -0.005 & -0.029 & 0.024 & 0.065 & 0.055 & 0.045 & 0.003 & -0.033 & -0.063 \\
\hline & $(0.078)$ & $(0.041)$ & $(0.070)$ & $(0.074)$ & $(0.068)$ & $(0.055)$ & $(0.059)$ & $(0.030)$ & $(0.055)$ & $(0.058)$ \\
\hline \multirow{2}{*}{ No Education Data } & $-0.187^{*}$ & 0.059 & -0.054 & -0.084 & -0.134 & 0.037 & $-0.111^{* *}$ & $0.170^{*}$ & 0.018 & 0.057 \\
\hline & $(0.106)$ & $(0.081)$ & $(0.103)$ & $(0.108)$ & $(0.085)$ & $(0.084)$ & $(0.054)$ & $(0.094)$ & $(0.092)$ & $(0.088)$ \\
\hline \multirow{2}{*}{ Child Is Female } & $-0.165^{* * *}$ & $0.038^{* *}$ & 0.021 & $-0.102^{* * *}$ & 0.010 & $0.068^{* * *}$ & $-0.092^{* * *}$ & $-0.051^{* *}$ & 0.018 & $0.098^{* * *}$ \\
\hline & $(0.030)$ & $(0.018)$ & $(0.032)$ & $(0.032)$ & $(0.032)$ & $(0.023)$ & $(0.028)$ & $(0.021)$ & $(0.024)$ & $(0.023)$ \\
\hline \multirow{2}{*}{ Child's Age } & -0.002 & $0.011^{* * *}$ & -0.005 & $-0.029^{* * *}$ & 0.002 & -0.008 & $-0.017^{* * *}$ & 0.003 & 0.006 & $0.024^{* * *}$ \\
\hline & $(0.007)$ & $(0.004)$ & $(0.007)$ & $(0.007)$ & $(0.007)$ & $(0.005)$ & $(0.005)$ & $(0.004)$ & $(0.005)$ & $(0.005)$ \\
\hline \multirow{2}{*}{ Child Is Black } & $-0.168^{* * *}$ & $-0.058^{*}$ & 0.062 & -0.072 & -0.021 & 0.032 & $0.101^{* *}$ & $0.073^{* *}$ & -0.007 & -0.007 \\
\hline & $(0.050)$ & $(0.035)$ & $(0.044)$ & $(0.048)$ & $(0.052)$ & $(0.034)$ & $(0.039)$ & $(0.031)$ & $(0.035)$ & $(0.035)$ \\
\hline \multirow{2}{*}{ Child Is Hispanic } & 0.065 & -0.012 & 0.060 & -0.072 & -0.011 & $0.117^{* *}$ & $0.189^{* * *}$ & $-0.091^{* * *}$ & $0.145^{* *}$ & $-0.136^{* * *}$ \\
\hline & $(0.070)$ & $(0.049)$ & $(0.071)$ & $(0.068)$ & $(0.067)$ & $(0.056)$ & $(0.068)$ & $(0.025)$ & $(0.070)$ & $(0.039)$ \\
\hline \multirow{2}{*}{ Central Region } & -0.073 & -0.027 & -0.014 & -0.028 & $-0.104^{* *}$ & -0.018 & -0.046 & -0.019 & $0.055^{*}$ & 0.056 \\
\hline & $(0.047)$ & $(0.029)$ & $(0.051)$ & $(0.051)$ & $(0.050)$ & $(0.039)$ & $(0.041)$ & $(0.023)$ & $(0.032)$ & $(0.036)$ \\
\hline \multirow{2}{*}{ Southern Region } & 0.014 & -0.022 & -0.007 & -0.041 & $-0.097 *$ & -0.014 & 0.012 & $0.061^{* *}$ & $0.110^{* * *}$ & 0.027 \\
\hline & $(0.049)$ & $(0.029)$ & $(0.051)$ & $(0.050)$ & $(0.051)$ & $(0.038)$ & $(0.042)$ & $(0.027)$ & $(0.034)$ & $(0.036)$ \\
\hline \multirow{2}{*}{ Western Region } & $0.099^{*}$ & 0.020 & -0.077 & 0.038 & -0.023 & 0.003 & 0.003 & 0.042 & 0.052 & 0.015 \\
\hline & $(0.056)$ & $(0.033)$ & $(0.054)$ & $(0.053)$ & $(0.057)$ & $(0.044)$ & $(0.047)$ & $(0.033)$ & $(0.036)$ & $(0.037)$ \\
\hline \multirow{2}{*}{ Rural Area } & 0.036 & 0.030 & 0.006 & -0.031 & $-0.064^{*}$ & -0.035 & 0.030 & 0.005 & -0.038 & 0.021 \\
\hline & $(0.038)$ & $(0.025)$ & $(0.036)$ & $(0.037)$ & $(0.037)$ & $(0.028)$ & $(0.034)$ & $(0.024)$ & $(0.027)$ & $(0.029)$ \\
\hline \multirow{2}{*}{ Constant } & $0.497^{* * *}$ & -0.025 & $0.394^{* * *}$ & $0.794^{* * *}$ & $0.512^{* * *}$ & 0.102 & $0.544^{* * *}$ & 0.029 & 0.024 & $-0.247^{* * *}$ \\
\hline & $(0.124)$ & $(0.086)$ & $(0.123)$ & $(0.125)$ & $(0.123)$ & $(0.097)$ & $(0.101)$ & $(0.068)$ & $(0.100)$ & $(0.083)$ \\
\hline Observations & 1582 & 1582 & 1582 & 1582 & 1582 & 1582 & 1582 & 1582 & 1582 & 1582 \\
\hline R-Squared & 0.094 & 0.045 & 0.037 & 0.056 & 0.048 & 0.053 & 0.063 & 0.068 & 0.053 & 0.086 \\
\hline
\end{tabular}

Note: Authors' estimates from linear regressions estimated using data for children aged 10 - 17 years in the CDS-II; estimates incorporate sampling weights. Robust standard errors clustered by family are shown in parentheses. ${ }^{* * *}$ Coefficient different from zero with $\mathrm{p}<0.01{ }^{* *}$ Coefficient different from zero with $\mathrm{p}<$ $0.05 ;{ }^{*}$ Coefficient different from zero with $\mathrm{p}<0.1$.

below 130 percent of the poverty threshold are more likely to report drinking coffee and less likely to report eating fruit at breakfast than children living in households with incomes above 185 percent of the poverty threshold (the omitted category in our models). Conditional on income being within one of the categories that we set, additional income is positively associated with juice consumption and negatively associated with snack consumption at breakfast.

Among the household composition variables, the number of children under six years of age is positively associated with toast consumption, while the number of chil- dren aged six to 18 years is positively associated with milk and fruit consumption. The number of adults in the household is negatively associated with toast consumption.

Living in a household with an employed head is associated with less egg consumption, and living in a household with an employed wife is associated with less milk consumption. Children who live in households with the least educated heads report consuming less milk, toast, fruit, and snacks than children with heads who are high school graduates. Girls report consuming less milk, cereal, eggs, and meat than boys but more coffee and fruit. 
As children age they report consuming more coffee and less cereal and eggs. Black children report consuming less milk and coffee than white children but more eggs and meat.

Table 4 displays the coefficients and standard errors from OLS models of the number of days in the preceding week that the children reported eating foods from different food categories. From left to right, the columns list coefficients and standard errors for the weekly consumption of milk and dairy, fruit, vegetables, grains, sweets, meat, and other protein, such as peanut butter. The rows display the estimates associated with the same independent variables as Table 3.

In general, there are fewer statistically significant associations among the programmatic variables. Children who participated in the SBP reported eating sweets on 0.4 more days in the preceding week than other children who did not participate. Participation in the NSLP and household participation in WIC were not significantly associated with weekly reported food consumption. SNAP receipt was negatively associated with meat consumption, but the needs-adjusted benefit level was positively associated. Evaluated at the mean of the benefit value, the net effect of SNAP was close to zero.

Among the other variables in the model, the number of children aged six to 18 years is positively associated with milk, sweet, and meat consumption, while the number of adults is positively associated with fruit consumption. The results also indicate that children living with household heads who are more educated consume more foods

Table 4. Linear models of weekly food consumption.

\begin{tabular}{|c|c|c|c|c|c|c|c|}
\hline \multirow{2}{*}{ VARIABLES } & (1) & (2) & (3) & (4) & (5) & (6) & (7) \\
\hline & Milk & Fruit & Veg. & Grains & Sweet & Meat & Protein \\
\hline \multirow{2}{*}{ School Breakfast } & 0.250 & 0.345 & -0.052 & -0.175 & $0.430^{*}$ & 0.047 & 0.047 \\
\hline & $(0.204)$ & $(0.219)$ & $(0.252)$ & $(0.178)$ & $(0.229)$ & $(0.204)$ & $(0.219)$ \\
\hline \multirow{2}{*}{ School Lunch } & -0.174 & -0.004 & 0.405 & -0.097 & -0.105 & 0.168 & 0.189 \\
\hline & $(0.192)$ & $(0.184)$ & $(0.250)$ & $(0.162)$ & $(0.226)$ & $(0.174)$ & $(0.185)$ \\
\hline \multirow{2}{*}{ Received WIC } & 0.460 & -0.319 & 0.005 & -0.255 & -0.316 & -0.379 & -0.126 \\
\hline & $(0.365)$ & $(0.298)$ & $(0.413)$ & $(0.327)$ & $(0.371)$ & $(0.335)$ & $(0.376)$ \\
\hline \multirow{2}{*}{ Received SNAP } & -0.409 & 0.190 & -0.658 & -0.227 & 0.105 & $-0.566^{*}$ & -0.113 \\
\hline & $(0.365)$ & $(0.352)$ & $(0.423)$ & $(0.347)$ & $(0.445)$ & $(0.305)$ & $(0.389)$ \\
\hline \multirow{2}{*}{ SNAP Value/Needs } & 1.635 & 1.592 & 1.750 & 0.085 & -1.513 & $3.660^{*}$ & -0.073 \\
\hline & $(1.985)$ & $(1.806)$ & $(2.598)$ & $(1.858)$ & $(2.587)$ & (1.911) & $(2.360)$ \\
\hline \multirow{2}{*}{ Income/Needs } & -0.001 & $0.019^{* *}$ & -0.001 & $-0.022^{* *}$ & 0.005 & -0.005 & -0.001 \\
\hline & $(0.007)$ & (0.009) & $(0.013)$ & $(0.009)$ & $(0.010)$ & $(0.007)$ & $(0.010)$ \\
\hline \multirow{2}{*}{ Income/Needs Is $>1.3 \&<1.85$} & 0.228 & 0.345 & -0.183 & 0.122 & -0.059 & $-0.393^{*}$ & -0.083 \\
\hline & $(0.221)$ & $(0.232)$ & $(0.281)$ & $(0.185)$ & $(0.255)$ & $(0.213)$ & $(0.217)$ \\
\hline \multirow{2}{*}{ Income/Needs Is $<1.3$} & -0.054 & -0.113 & 0.095 & 0.267 & 0.112 & -0.319 & -0.201 \\
\hline & $(0.231)$ & $(0.239)$ & $(0.291)$ & $(0.185)$ & $(0.263)$ & $(0.259)$ & $(0.234)$ \\
\hline \multirow{2}{*}{$\#$ of Children $<6$} & -0.077 & -0.030 & 0.254 & -0.078 & -0.025 & -0.056 & 0.038 \\
\hline & $(0.132)$ & $(0.132)$ & $(0.175)$ & $(0.110)$ & $(0.163)$ & $(0.151)$ & $(0.158)$ \\
\hline \multirow{2}{*}{ \# of Children between 6 and 18} & $0.114^{*}$ & 0.026 & 0.122 & 0.027 & $0.124^{*}$ & $0.117^{* *}$ & 0.058 \\
\hline & $(0.058)$ & $(0.069)$ & $(0.084)$ & $(0.047)$ & $(0.069)$ & $(0.056)$ & $(0.066)$ \\
\hline \multirow{2}{*}{$\#$ of Adults $>18$} & 0.089 & $0.239^{* *}$ & -0.035 & 0.038 & 0.015 & -0.171 & 0.027 \\
\hline & $(0.090)$ & $(0.100)$ & $(0.132)$ & $(0.096)$ & $(0.138)$ & $(0.112)$ & $(0.103)$ \\
\hline \multirow{2}{*}{ Head Is Married } & 0.027 & 0.055 & 0.278 & -0.159 & -0.214 & 0.330 & -0.170 \\
\hline & $(0.216)$ & $(0.241)$ & $(0.274)$ & $(0.210)$ & $(0.258)$ & $(0.241)$ & $(0.242)$ \\
\hline
\end{tabular}


Continued

\begin{tabular}{|c|c|c|c|c|c|c|c|}
\hline \multirow{2}{*}{ Head Is Employed } & 0.147 & $0.346^{*}$ & 0.318 & 0.099 & 0.120 & -0.069 & -0.103 \\
\hline & $(0.195)$ & $(0.205)$ & $(0.238)$ & $(0.175)$ & $(0.228)$ & $(0.199)$ & $(0.215)$ \\
\hline \multirow{2}{*}{ Wife Is Employed } & -0.154 & -0.028 & 0.016 & 0.109 & 0.257 & -0.041 & 0.148 \\
\hline & $(0.151)$ & $(0.183)$ & $(0.226)$ & $(0.143)$ & $(0.186)$ & $(0.173)$ & $(0.171)$ \\
\hline \multirow{2}{*}{$\begin{array}{l}\text { Head Did Not Attend High } \\
\text { School }\end{array}$} & $-0.790^{* *}$ & -0.035 & 0.158 & 0.210 & -0.161 & -0.496 & -0.382 \\
\hline & $(0.365)$ & $(0.308)$ & $(0.484)$ & $(0.246)$ & $(0.422)$ & $(0.379)$ & $(0.401)$ \\
\hline \multirow{2}{*}{$\begin{array}{l}\text { Head Did Not Grad. High } \\
\text { School }\end{array}$} & $-0.393^{*}$ & -0.437 & $-0.559^{*}$ & 0.105 & 0.077 & 0.109 & -0.347 \\
\hline & $(0.228)$ & $(0.332)$ & $(0.304)$ & $(0.193)$ & $(0.277)$ & $(0.260)$ & $(0.273)$ \\
\hline \multirow{2}{*}{ Head Attended Some College } & 0.122 & $0.349^{* *}$ & $0.407^{* *}$ & 0.193 & -0.145 & -0.068 & 0.151 \\
\hline & $(0.162)$ & $(0.173)$ & $(0.203)$ & $(0.141)$ & $(0.193)$ & $(0.176)$ & $(0.177)$ \\
\hline \multirow{2}{*}{ Head Is College Graduate } & 0.202 & 0.228 & $0.657^{* * *}$ & $0.420^{* * *}$ & 0.085 & -0.054 & -0.063 \\
\hline & $(0.159)$ & $(0.176)$ & $(0.199)$ & $(0.129)$ & $(0.188)$ & $(0.157)$ & $(0.166)$ \\
\hline \multirow{2}{*}{ Head Has a Graduate Degree } & $0.535^{* * *}$ & -0.060 & $1.017^{* * *}$ & $0.915^{* * *}$ & 0.418 & -0.024 & $0.505^{*}$ \\
\hline & $(0.196)$ & $(0.315)$ & $(0.332)$ & $(0.163)$ & $(0.297)$ & $(0.259)$ & $(0.297)$ \\
\hline \multirow{2}{*}{ No Education Data } & 0.122 & -0.307 & -0.136 & -0.050 & 0.068 & 0.476 & -0.024 \\
\hline & $(0.285)$ & $(0.514)$ & $(0.377)$ & $(0.479)$ & $(0.454)$ & $(0.307)$ & $(0.354)$ \\
\hline \multirow{2}{*}{ Child Is Female } & $-0.329^{* * *}$ & 0.120 & $0.247^{*}$ & $0.205^{* *}$ & -0.041 & -0.044 & $-0.293^{* *}$ \\
\hline & $(0.109)$ & $(0.127)$ & $(0.141)$ & $(0.095)$ & $(0.129)$ & $(0.119)$ & $(0.129)$ \\
\hline \multirow{2}{*}{ Child's Age } & 0.036 & -0.009 & 0.048 & $0.081^{* * *}$ & $0.063^{* *}$ & $0.212^{* * *}$ & 0.021 \\
\hline & $(0.024)$ & $(0.026)$ & $(0.031)$ & $(0.019)$ & $(0.027)$ & $(0.026)$ & $(0.029)$ \\
\hline \multirow{2}{*}{ Child Is Black } & $-0.821^{* * *}$ & 0.281 & -0.330 & $-0.396^{* *}$ & 0.189 & $0.335^{* *}$ & -0.242 \\
\hline & $(0.193)$ & $(0.199)$ & $(0.228)$ & $(0.165)$ & $(0.183)$ & $(0.168)$ & $(0.193)$ \\
\hline \multirow{2}{*}{ Child Is Hispanic } & -0.328 & 0.154 & $-0.859^{* *}$ & -0.091 & -0.521 & 0.250 & $0.889^{* * *}$ \\
\hline & $(0.259)$ & $(0.292)$ & $(0.341)$ & $(0.174)$ & $(0.333)$ & $(0.262)$ & $(0.272)$ \\
\hline \multirow{2}{*}{ Central Region } & 0.021 & -0.145 & -0.375 & -0.120 & -0.028 & -0.009 & 0.153 \\
\hline & $(0.185)$ & $(0.189)$ & $(0.241)$ & $(0.149)$ & $(0.227)$ & $(0.191)$ & $(0.188)$ \\
\hline \multirow{2}{*}{ Southern Region } & -0.065 & $-0.503^{* *}$ & -0.186 & -0.179 & -0.030 & -0.048 & $0.451^{* *}$ \\
\hline & $(0.183)$ & $(0.200)$ & $(0.246)$ & $(0.149)$ & $(0.208)$ & $(0.198)$ & $(0.190)$ \\
\hline \multirow{2}{*}{ Western Region } & 0.113 & -0.287 & -0.172 & -0.262 & 0.025 & -0.278 & 0.217 \\
\hline & $(0.190)$ & $(0.211)$ & $(0.258)$ & $(0.162)$ & $(0.236)$ & $(0.223)$ & $(0.209)$ \\
\hline \multirow{2}{*}{ Rural Area } & 0.003 & -0.052 & -0.025 & -0.019 & -0.016 & 0.111 & 0.027 \\
\hline & $(0.138)$ & $(0.152)$ & $(0.173)$ & $(0.124)$ & $(0.172)$ & $(0.151)$ & $(0.154)$ \\
\hline \multirow{2}{*}{ Constant } & $4.689^{* * *}$ & $4.053^{* * *}$ & $2.650^{* * *}$ & $4.595^{* * *}$ & $3.441^{* * *}$ & $2.348^{* * *}$ & $3.136^{* * *}$ \\
\hline & $(0.468)$ & $(0.521)$ & $(0.640)$ & $(0.383)$ & $(0.511)$ & $(0.498)$ & $(0.545)$ \\
\hline Observations & 1564 & 1573 & 1571 & 1576 & 1573 & 1572 & 1563 \\
\hline R-Squared & 0.087 & 0.043 & 0.082 & 0.085 & 0.033 & 0.085 & 0.036 \\
\hline
\end{tabular}

Note: Authors' estimates from linear regressions estimated using data for children aged 10 - 17 years in the CDS-II; estimates incorporate sampling weights. Robust standard errors clustered by family are shown in parentheses. ${ }^{* * *}$ Coefficient different from zero with $\mathrm{p}<0.01 ;{ }^{* *}$ Coefficient different from zero with $\mathrm{p}<$ $0.05 ;{ }^{*}$ Coefficient different from zero with $\mathrm{p}<0.1$ 
than children living with less educated heads. The estimates also indicate that girls consume vegetables and grains on more days than boys but consume milk and other proteins on fewer days. Older children consume grains, sweets, and meat on more days than younger children. Black children consume milk and grains on fewer days than white children but consume sweets on more days. Hispanic children consume fewer vegetables but more other proteins.

The models in Tables 3 and $\mathbf{4}$ were estimated using the entire analysis sample of children from the CDS-II. Arguably, however, the food consumption patterns of children living in higher income households might not be comparable to those of children living in lower income households because of the differences in resources. Children in higher income households also would not be eligible for food assistance. We have re-estimated the models of breakfast consumption and weekly food consumption using a restricted sample of children who lived in households with incomes below 185 percent of the poverty threshold. These households would have been income eligible for reduced-price school meals and for
WIC, and modest changes in income would have made them eligible for SNAP and free school meals. A drawback of this analysis is that it reduces our sample size by more than two-thirds. We report results for the programmatic and economic measures from these specifications in Tables $\mathbf{5}$ and $\mathbf{6}$.

Overall, the breakfast results for low-income children in Table 5 are similar to those for the sample as a whole. Free or reduced school breakfast is associated with significantly increased probabilities of juice $(+18 \%)$, fruit $(+19 \%)$, and snack food $(+16 \%)$ consumption at breakfast, all three of which were also positive in the full sample. Children who received subsidized school lunches were 12 percentage points more likely to drink milk or eat dairy products for breakfast than other low-income children, although the estimate falls short of being statistically significant. Children in families that received WIC were significantly more likely to eat snacks and less likely to eat toast, results that accord with the full-sample estimates. However, estimates for the associations between WIC participation and milk and cereal consumption are smaller in the low-income sample and lose their

Table 5. Breakfast consumption in low income families.

\begin{tabular}{|c|c|c|c|c|c|c|c|c|c|c|}
\hline \multirow{2}{*}{ VARIABLES } & (1) & (2) & (3) & (4) & (5) & (6) & (7) & (8) & (9) & (10) \\
\hline & Milk & Coffee & Juice & Cereal & Toast & Fruit & Eggs & Meat & Snacks & Other \\
\hline \multirow{2}{*}{ School Breakfast } & 0.050 & -0.000 & $0.182^{* * *}$ & 0.100 & 0.014 & $0.190^{* * *}$ & 0.033 & 0.037 & $0.165^{* * *}$ & -0.037 \\
\hline & $(0.078)$ & $(0.059)$ & $(0.065)$ & $(0.073)$ & $(0.063)$ & $(0.059)$ & $(0.064)$ & $(0.046)$ & $(0.054)$ & $(0.046)$ \\
\hline \multirow{2}{*}{ School Lunch } & 0.122 & -0.034 & -0.037 & 0.029 & -0.034 & -0.065 & -0.005 & 0.050 & -0.052 & 0.003 \\
\hline & $(0.086)$ & $(0.066)$ & $(0.071)$ & $(0.074)$ & $(0.081)$ & $(0.049)$ & $(0.076)$ & $(0.051)$ & $(0.048)$ & $(0.052)$ \\
\hline \multirow{2}{*}{ Received WIC } & 0.141 & 0.036 & 0.143 & 0.012 & $-0.240^{* * *}$ & -0.015 & -0.071 & 0.099 & $0.218^{* * *}$ & -0.049 \\
\hline & $(0.102)$ & $(0.072)$ & $(0.095)$ & $(0.105)$ & $(0.077)$ & $(0.080)$ & $(0.087)$ & $(0.065)$ & $(0.081)$ & $(0.055)$ \\
\hline \multirow{2}{*}{ Received SNAP } & $-0.190^{*}$ & -0.064 & -0.065 & $0.175^{*}$ & -0.142 & -0.057 & 0.039 & 0.115 & 0.024 & -0.070 \\
\hline & $(0.114)$ & $(0.064)$ & $(0.092)$ & $(0.090)$ & $(0.107)$ & $(0.080)$ & $(0.109)$ & $(0.072)$ & $(0.089)$ & $(0.043)$ \\
\hline \multirow{2}{*}{ SNAP Value/Needs } & 0.586 & 0.332 & -0.355 & $-1.275^{* *}$ & 0.608 & 0.311 & -0.724 & $-1.346^{* * *}$ & -0.484 & $0.606^{*}$ \\
\hline & $(0.738)$ & $(0.517)$ & $(0.586)$ & $(0.544)$ & $(0.641)$ & $(0.476)$ & $(0.669)$ & $(0.396)$ & $(0.530)$ & $(0.342)$ \\
\hline \multirow{2}{*}{ Income/Needs } & -0.055 & $0.152^{*}$ & -0.125 & -0.056 & -0.114 & $0.122^{*}$ & $0.142^{*}$ & 0.028 & 0.071 & $-0.166^{* *}$ \\
\hline & $(0.080)$ & $(0.083)$ & $(0.096)$ & $(0.094)$ & $(0.096)$ & $(0.066)$ & $(0.076)$ & $(0.055)$ & $(0.059)$ & $(0.073)$ \\
\hline \multirow{2}{*}{ Income/Needs is $<1.3$} & -0.058 & $0.221^{* * *}$ & $-0.181^{* *}$ & -0.039 & -0.084 & -0.045 & $0.121^{*}$ & 0.009 & -0.001 & $-0.187^{* * *}$ \\
\hline & $(0.092)$ & $(0.070)$ & $(0.085)$ & $(0.087)$ & $(0.079)$ & $(0.065)$ & $(0.070)$ & $(0.051)$ & $(0.059)$ & $(0.067)$ \\
\hline Observations & 494 & 494 & 494 & 494 & 494 & 494 & 494 & 494 & 494 & 494 \\
\hline R-Squared & 0.197 & 0.165 & 0.179 & 0.113 & 0.099 & 0.151 & 0.131 & 0.148 & 0.130 & 0.160 \\
\hline
\end{tabular}

Note: Authors' estimates from linear regressions estimated using data for children aged 10 - 17 years living in households with incomes below 185 percent of the poverty line in the CDS-II. The models also include controls for family structure, parents' employment status, the family head's education, the child's gender, age, and race/ethnicity, the region of residence, and urban residence. The estimates incorporate sampling weights. Robust standard errors clustered by family are shown in parentheses. ${ }^{*}$ Coefficient different from zero with $\mathrm{p}<0.01$; ${ }^{* *}$ Coefficient different from zero with $\mathrm{p}<0.05$; ${ }^{*}$ Coefficient different from zero with $\mathrm{p}<0.1$. 
Table 6. Weekly food consumption in low income families.

\begin{tabular}{lcccccccc}
\hline \multirow{2}{*}{ VARIABLES } & $(1)$ & $(2)$ & $(3)$ & $(4)$ & $(5)$ & $(6)$ & $(7)$ \\
\cline { 2 - 7 } & Milk & Fruit & Veg. & Grains & Sweet & Meat & Protein \\
\hline School Breakfast & 0.171 & $0.617^{* *}$ & 0.159 & -0.111 & $0.660^{* *}$ & 0.100 & 0.263 \\
School Lunch & $(0.224)$ & $(0.283)$ & $(0.325)$ & $(0.194)$ & $(0.260)$ & $(0.266)$ & $(0.287)$ \\
& -0.295 & -0.273 & -0.023 & -0.151 & 0.002 & 0.119 & -0.352 \\
Received WIC & $(0.234)$ & $(0.275)$ & $(0.415)$ & $(0.210)$ & $(0.317)$ & $(0.245)$ & $(0.294)$ \\
& -0.107 & -0.217 & -0.515 & -0.288 & $-0.985^{* *}$ & $-0.764^{* *}$ & -0.086 \\
Received SNAP & $(0.411)$ & $(0.343)$ & $(0.458)$ & $(0.387)$ & $(0.400)$ & $(0.368)$ & $(0.471)$ \\
& -0.396 & -0.053 & -0.715 & -0.311 & 0.239 & $-0.609^{*}$ & 0.072 \\
SNAP Value/Needs & $(0.340)$ & $(0.458)$ & $(0.502)$ & $(0.329)$ & $(0.384)$ & $(0.355)$ & $(0.490)$ \\
& 1.275 & 1.440 & 0.490 & 0.409 & 0.331 & 2.531 & -3.605 \\
Income/Needs & $(2.511)$ & $(2.551)$ & $(3.556)$ & $(2.179)$ & $(2.792)$ & $(2.223)$ & $(2.873)$ \\
Income/Needs Is $<1.3$ & $-0.992^{* * *}$ & -0.239 & -0.280 & -0.118 & -0.375 & 0.047 & -0.115 \\
Observations & $(0.316)$ & $(0.381)$ & $(0.454)$ & $(0.260)$ & $(0.391)$ & $(0.318)$ & $(0.391)$ \\
R-Squared & $-1.051^{* * *}$ & -0.563 & 0.018 & -0.102 & -0.330 & -0.122 & -0.232 \\
\hline
\end{tabular}

Note: Authors' estimates from linear regressions estimated using data for children aged 10 - 17 years living in households with incomes below 185 percent of the poverty line in the CDS-II. The models also include controls for family structure, parents' employment status, the family head's education, the child's gender, age, and race/ethnicity, the region of residence, and urban residence. The estimates incorporate sampling weights. Robust standard errors clustered by family are shown in parentheses. ${ }^{* * *}$ Coefficient different from zero with $\mathrm{p}<0.01 ;{ }^{* *}$ Coefficient different from zero with $\mathrm{p}<0.05$; ${ }^{*}$ Coefficient different from zero with $\mathrm{p}<0.1$.

statistical significance. In the low-income sample, SNAP participation is associated with less milk consumption and more cereal consumption, while the value of SNAP benefits is associated with less cereal and meat consumption.

For Table 6, weekly foods eaten by children in lowincome families, results are again similar to those of the full sample. School breakfast subsidies are still associated with significantly greater weekly sweets consumption $(+0.7$ days) and with increased fruit consumption $(+0.6$ days). As with the full sample, low-income children who received school lunches still have no statistically significant differences in the number of days that foods are eaten in a week. However, children in families that participated in the WIC program ate meat $(-1.0$ days $)$ and sweets ( -0.8 days) less often than children in other families; this makes some sense, as these are not food types subsidized by the program. Finally, participation in SNAP has very similar results to those of the full sample, and only meat consumption has a statistically significant coefficient ( -0.6 days for SNAP recipients).

\section{Conclusions}

In this article, we used 2002-2003 data from the second
Child Development Supplement of the Panel Study of Income Dynamics to examine the association between households' participation in the SNAP, SBP, NLSP, and WIC and individual 10 - 17 year-old children's reports of breakfast and weekly food consumption. Our study contributes to the literature on the effectiveness of food assistance programs in two ways. First, it considers participation in all of the major food assistance programs. Despite the frequency of multiple program participation among low-income families with children [13], few studies have examined the direct effects of these programs together. Second, our study adds to our knowledge about the sharing of food assistance between family members who are and are not targeted for benefits. In particular, we examine how WIC assistance that is intended for pregnant women, mothers, infants, and very young children may benefit older children.

Results from our analyses provide some evidence that is consistent with sharing. Our estimates indicate that WIC participation by others in the household is associated with increased consumption of milk and cereal at breakfast by older children. WIC participation is also associated with increased consumption of snacks and decreased consumption of toast at breakfast. 
Looking at programs that are targeted towards the children directly, we find that participation in the SBP is associated with increased consumption of juice, fruit, and snacks at breakfast and sweets during the week. Participation in the NSLP is associated with increased consumption of milk. The receipt of SNAP is estimated to reduce the consumption of toast and fruit at breakfast and the consumption of meat over the week. However, conditional on receiving SNAP, additional benefits are associated with increased consumption of juice at breakfast, decreased consumption of toast at breakfast, and increased consumption of meat through the week.

A strength of our analysis is the rich set of observed economic, demographic, and geographic controls that we are able to include from the PSID. Studies based on other food consumption surveys have generally had fewer controls. That said, our analyses do not include more sophisticated controls for the likely endogeneity of participation in the different food assistance programs. Thus, we are limited in our ability to make causal inferences.

\section{Acknowledgements}

The authors gratefully acknowledge financial support from the Economic Research Service of the US Department of Agriculture (USDA) under Food Assistance and Nutrition Research Program Cooperative Agreement no. 58-4000-0-0025. They also thank Laura Tiehen for her help and advice, and Mark Prell for his helpful comments. The views expressed in this paper are those of the authors and do not necessarily reflect those of the USDA.

\section{REFERENCES}

[1] V. Oliveira, "The Food Assistance Landscape, FY 2009 Annual Report," Economic Information Bulletin, No. EIB-6-7, Economic Research Service, Washington, 2010.

[2] M. K. Fox, W. Hamilton and B.-H. Lin, "Effects of Food Assistance and Nutrition Programs on Nutrition and Health: Volume 3, Literature Review," Food Assistance and Nutrition Research Report No. 19-3, Economic Research Service, Washington, 2004.
[3] D. J. Besharov and P. Germanis, "Evaluating WIC," Evaluation Review, Vol. 24, No. 2, 2000, pp. 123-190. doi:10.1177/0193841X0002400201

[4] V. Oliveira and R. Chandran, "Children's Consumption of WIC-Approved Foods," Food Assistance and Nutrition Research Report No. 44, Economic Research Service, Washington, 2005.

[5] S. Long, "Do the School Nutrition Programs Supplement Household Food Expenditures?" Journal of Human Resources, Vol. 26, No. 4, 1991, pp. 654-678. doi: $10.2307 / 145979$

[6] M. VerPloeg, "Do Benefits of US Food Assistance Programs for Children Spillover to Older Children in the Same Household?" Journal of Family Economic Issues, Vol. 30, No. 4, 2009, pp. 412-427. doi:10.1007/s10834-009-9164-9

[7] V. Oliveira and C. Gundersen, "WIC and the Nutrient Intake of Children," Food Assistance and Nutrition Research Report No. 5, Economic Research Service, Washington, 2000.

[8] G. J. Arcia, L. A. Crouch and R. A. Kulka, "Impact of the WIC Program on Food Expenditures," American Journal of Agricultural Economics, Vol. 72, No. 1, 1990, pp. 218-226. doi: $10.2307 / 1243161$

[9] A. Ishdorj, H. H. Jensen and J. Tobias, "Intra-Household Allocation and Consumption of WIC-Approved Foods: A Bayesian Approach," Advances in Econometrics, Vol. 23, 2008, pp. 157-182. doi:10.1016/S0731-9053(08)23005-7

[10] D. Rose, J.-P. Habicht and B. Devaney, "Household Participation in the Food Stamp and WIC Programs Increases the Nutrient Intakes of Preschool Children," Journal of Nutrition, Vol. 128, No. 3, 1998, pp. 548-555.

[11] J. Bhattacharya, J. Currie and S. Haider, "Breakfast of Champions? The School Breakfast Program and the Nutrition of Children and Families," Journal of Human Resources, Vol. 41, No. 3, 2006, pp. 445-466.

[12] Beltsville Human Nutrition Research Center, "Breakfast in America, 2001-2002," 2011.

http://www.ars.usda.gov/SP2UserFiles/Place/12355000/p df/DBrief/1_Breakfast_2001_2002.pdf

[13] C. Newman, J. Todd and M. VerPloeg, “Children's Participation in Multiple Food Assistance Programs: Changes from 1990 to 2008," Social Service Review, in Press. 